Ben Nevis Observatory and the Argentine Republic.

News has reached me here from the office of the Scottish National Antarctic Expedition in Edinburgh of the appointment of almost the whole of the Ben Nevis Observatory staff to the Argentine Meteorological Office, including the superintendent, Mr. Angus Rankin, who has been associated with the observatory for more than twenty years, Mr. Robert Macdougal, for many years assistant, and Mr. Bee.

It may be remembered that in March, 1903, the Scottish National Antarctic Expedition set up a first-class meteorological and magnetical station in the South Orkneys, at Scotia Bay, and that, after the wintering of the Scotia, I offered to hand over the station, including Omond House and Copeland Observatory, to the Argentine Government with eighteen months' provisions, as well as to give a passage on board the Scotia to Argentine men of science if the Republic would undertake to continue the work and relieve the party the following year. This was carried through by the energy of Mr. Walter G. Davis, director of the Argentine Meteorological Office, and Mr. Robert C. Mossman, the Scottish expedition's meteorologist, was asked to continue in charge. Now Mr. Mossman has returned after two years' valuable work in the Antarctic, and the station is being kept up a third year-the first time in the history of Antarctic exploration that scientific observations have been carried on in one place for more than two years.

But the Republic is not satisfied; it is to continue the work for still another year, and is even going to increase the number of Antarctic stations. Trained men were required, and since Mr. Mossman's return he has been in communication with Mr. Davis, with the result that these three gentlemen have been appointed to carry on this work, as well as Mr. W. R. Bruce, also of Ben Nevis Observatory, who arrived in Buenos Aires three weeks ago.

The Argentine Republic must be congratulated on its enlightened perspective; but surely while doing so we must hang our heads in shame, for, while our Government has discouraged scientific research, we find this rapidly rising Republic eager to encourage it.

Eggishorn. Switzerland, September 8.

$$
\text { William S. Bruce. }
$$

\section{Properties of Photographic Plates Exposed to Light.}

In May, I904, I exposed an ordinary sensitised $\frac{I}{4}$ plate (2oth Century Rapid) to daylight. It was so placed that the light had to pass through a window before falling upon the plate. The day was cloudy and dull, without sun, and the time of exposure was from two to four p.m.

In the meantime I placed an unexposed plate in a box, and upon it a steel pair of scissors. Then taking the exposed plate I placed it above the unexposed plate with the scissors in between and in contact with the sensitised sides of both plates.

After closing the box and wrapping up to exclude light, I put it away for six weeks.

At the end of this period I developed (with MQ) the unexposed plate, and found, as I had hoped, a radiograph of the scissors; then developing the exposed plate it appeared, if anything, to be less dark than the unexposed plate, but without any image.

During 1904 I repeated the experiment several times, varying the time of exposure and letting the light pass through thicker glass, also developing at shorter intervals, the days in every case being cloudy as in the first case. With one slight exception, I failed to obtain any result.

This year I put down three other pairs under the same conditions as the first experiment of Igo4, but, if anything, the day, though cloudy, was much brighter. With these I obtained three good results, one of which I unforturiately spoilt in developing.

At present I have five or six other pairs which will be ready for development in four or five weeks' time. In these cases the day was bright sunshine, so that perhaps better results may be expected.

Coombe College, Luton Road, Harpenden. L. H. Wisv.

\section{CAUSE AND PREVENTION OF DUST FROM AUTOMOBILES.}

$A \mathrm{~T}$ the present time by far the most serious A problem which the automobilist has to face is the abatement of the "dust nuisance." A great deal of bad feeling has arisen against the motorist on account of the dust which he too frequently produces, and there is no doubt that there are very good grounds for the irritation which has arisen, more particularly in agricultural districts. Farming in this country, at the best of times, is not in a prosperous condition, and a farmer does not view with any kindly eye a further reduction in his produce through the effects of dust. Apart from that, however, dust may cause a great deal of personal discomfort to other users of the roads; but this phase of the question would, perhaps, not require very serious consideration were it not that dust of this nature is apt to carry disease, and to lower the health of the poorer part of our population living along the main thoroughfares. As such matters may lead to serious opposition to automobilism, and possibly to further legal restrictions, all tending to hamper a growing and very important industry in this country, it is becoming imperative to see what can be done to minimise a nuisance of this kind.

At present there are two distinct methods of tackling the problem. One is to treat the roads, or construct them, in some way so that they no longer give rise to dust. The other is to so alter the construction of the car that dust, if it exists, will not be raised to a serious extent. These two methods we will now consider.

\section{(I) Special Treatment of the Roads.}

Undoubtedly proper treatment of the roads, if something permanent and at the same time not costly could be devised, would be the most effective solution of the problem. If, for example, the surface could remain moist, there would obviously be no dust. But treatment with the ordinary watering-cart is very transient; moreover, it is destructive, for the water, as a rule, is used in excess. The use of a deliquescent substance, such as calcium chloride, naturally suggests itself. But in order to be effective the solution would have to be above a certain strength, and probably a little wet weather would remove so much of the deliquescent material that re-treatment would be necessary very soon.

A number of solutions are now on the market for the more or less temporary treatment of roads. Perhaps the best known is Westrumite, containing chiefly petroleum and ammonia, the product being completely miscible with water. It has been used extensively as a temporary measure. Experiments by the Scottish Automobile Club show that the effect remains for a considerable time. Three stretches of road, each about half a mile in length, comprising metalling in three different stages of wear, were selected. These were thoroughly cleaned and treated with a Io per cent. solution of Westrumite. This was repeated after three days, and, as very heavy rain fell soon after, a solution of the same strength was applied a third time. The result appears to have been very satisfactory. Absolutely no dust was raised by vehicles of any description passing over the road for a very considerable time after the application, and even after three months the dust was nothing to speak of. On the metalling that had been worn the dust was found to be greater. The permanency of the result probably depends on the amount of traffic, as results elsewhere have not always been so satisfactory.

Other preparations of a similar character have

NO. I 872 , VOL. 72$]$ 